\section{PSQ-074 FAMPRIDINE RELATED ATRIAL FIBRILLATION: TWO CASE REPORTS}

'B Tauste Hernández, ${ }^{1}$ E Tejedor Tejada, ${ }^{2}$ I Andrade Andrade, ${ }^{1}$ I Alferez García*. ${ }^{1}$ Hospital Torrecárdenas, Pharmacy, Almería, Spain; ${ }^{2}$ Hospital Torrecárdenas, Neurology Unit, Almería, Spain

10.1136/ejhpharm-2020-eahpconf.391

Background and importance Fampridine (4-aminopyridine) is a drug whose indication is to improve gait in adult patients with multiple sclerosis with walking disability (EDSS 4-7). It is important to describe adverse effects that occur in certain patients in order to prevent them in the future.

Aim and objectives To describe two cases of atrial fibrillation in patients who were being treated with fampridine and its possible relationship.

Material and methods This was a case evaluation of two patients, aged 68 and 74 years, diagnosed with progressive secondary multiple sclerosis, recently receiving treatment with fampridine at a dose of $10 \mathrm{mg}$ every 12 hours. Both patients presented with arterial hypertension and took angiotensin converting enzyme inhibitors. They were referred to the emergency department after arrhythmic cardiorespiratory auscultation and generalised weakness. The following constants were measured to confirm the pathology: systolic arterial blood pressure (SABP), diastolic blood pressure (DBP), temperature $(\mathrm{Ta})$, oxygen saturation $(\mathrm{SaO})$ and heart rate (HR). In addition, an ECG and a complete analysis were performed. The degree of drug/adverse reaction causality was evaluated using the Naranjo algorithm.

Results Both patients remained in the emergency area until the results of the examination were obtained. The mean results of the constant measurements were: $\mathrm{SABP}=140 \mathrm{~mm} \mathrm{Hg}$, $\mathrm{DBP}=85 \mathrm{~mm} \mathrm{Hg}, \mathrm{Ta}=36^{\circ} \mathrm{C}, \mathrm{SaO}=95 \%$ and $\mathrm{HR}=105$ beats $/$ min. There were no signs of ischaemia and/or blockages on the ECG in either of the cases, the haemogram was normalised for age and biochemistry was not altered. Once the constants within the range had been established, they were discharged from hospital. In both cases, oral anticoagulants (acenocumarol) were prescribed, and in one case digoxin $(0.5$ $\mathrm{mg} /$ day), with the consequent suspension of fampridine. Naranjo's algorithm established the causality relationship as 'probable' (score of 5). The regional pharmacovigilance centre was notified by yellow card.

Conclusion and relevance The fampridine data sheet describes tachycardia as a rare adverse effect but does not describe atrial fibrillation. In our patients, there was the previous existence of arterial hypertension. Therefore, we consider it important to monitor hypertension and heart rate in patients treated with this drug. The need to notify the pharmacovigilance centre by means of the yellow sheet should also be noted.

\section{REFERENCES AND/OR ACKNOWLEDGEMENTS}

No conflict of interest.

\section{PSQ-075 SAFETY PROFILE OF FINGOLIMOD IN REAL WORLD CLINICAL PRACTICE: A PRELIMINARY STUDY}

MJ Morales Lara*, A Luna Higuera, A Linares Alarcón. Hospital Regional Universitario Carlos Haya, Pharmacy, Malaga, Spain

10.1136/ejhpharm-2020-eahpconf.392
Background and importance Fingolimod is an approved drug for relapsing-remitting multiple sclerosis (RRMS). Oral treatments allow better quality of life than injectable drugs but are not harmless.

Aim and objectives To assess fingolimod safety in patients with RRMS in clinical practice.

Material and methods A cross sectional, retrospective, observational study was conducted in a cohort of patients diagnosed with RRMS from a referral hospital in this pathology. A random sample was taken from the total number of treated patients during 2016-2017. The following variables were collected: demographics, and clinical and therapeutic variables (treatment duration, adverse events (AE), and causes of treatment discontinuation and dosing reduction by extension of administration interval to 48 hours).

Results Fifty patients were included (mean age $41.6 \pm 9$ years, $64 \%$ women) and mean duration of therapy was $3.4 \pm 2.5$ years.

AE reported during treatment were: lymphopenia/leucopenia $90 \%$ (grade 4, 2\%; grade 3, 58\%; grade 2, 28\%; and grade 1, 2\%); ocular (2\% maculopathy); cardiac (2\% first degree atrioventricular block during the first dose); gastrointestinal (6\%); dermatological (6\%: 2\% alopecia, 2\% dermographism and $2 \%$ skin rash); biochemical alterations (22\% elevation of transaminases, $10 \%$ hypercholesterolaemia and/or hypertriglyceridaemia); infections (4\% recurrent urinary infections); and CNS (4\% headaches/migraines).

Definitive interruption of therapy was performed in $10 \%$ of patients. Causes were: maculopathy, dermographism, atrioventricular block, elevated transaminase levels and oncological lesion. In $4 \%$ of patients, temporary discontinuation of therapy was carried out until resolution or improvement in $\mathrm{AE}$ (2\% grade 4 lymphopenia and $2 \%$ severe hypertransaminasaemia). In $24 \%$ of patients, an extension of the drug interval to 48 hours was performed to minimise drug exposure and to reduce the intensity of $\mathrm{AE}(22 \%$ grade 3 lymphopenia and $2 \%$ hypertransaminasaemia).

Conclusion and relevance The most common undesirable effect in our study population was lymphopenia/leucopenia, followed by transient elevation in liver enzymes, as described in the drug's summary of product characteristics. The extension of the drug interval to 48 hours is an efficient alternative in those patients with good response to the drug but who develop AE that may compromise the success of therapy. Prospective studies with a larger sample size are needed to confirm these preliminary results.

\section{REFERENCES AND/OR ACKNOWLEDGEMENTS}

No conflict of interest.

\section{PSQ-076 PRESCRIPTION MEDICATION SHARING AMONG ADULTS IN SAUDI ARABIA: A CROSS SECTIONAL SURVEY STUDY}

F Alhomoud*. Imam Abdulrahman Bin Faisal University, Department of Pharmacy PracticeCollege of Clinical Pharmacy, Dammam, Saudi Arabia

\subsection{6/ejhpharm-2020-eahpconf.393}

Background and importance Prescription medication sharing (PMS) has been associated with numerous adverse health outcomes. ${ }^{1}$ Despite the risks associated with this behaviour, very little is known about prescription medication sharing. ${ }^{1}$ 